\title{
Risk stratification of HCC occurrence after HCV eradication: a complicate plot of risk factors related and unrelated to the previous viral disease
}

\author{
Valentina Cossiga, Maria Guarino, Filomena Morisco, Nicola Caporaso \\ Gastroenterology Unit, Department of Clinical Medicine and Surgery, University of Naples "Federico II", Naples, Italy \\ Correspondence to: Maria Guarino, MD. Gastroenterology Unit, Department of Clinical Medicine and Surgery, University of Naples "Federico II", \\ Via S. Pansini, 5-80131 Naples, Italy. Email: maria.guarino86@gmail.com. \\ Provenance and Peer Review: This article was commissioned by the editorial office, Hepatobiliary Surgery and Nutrition. The article did not undergo \\ external peer review. \\ Comment on: Ioannou GN, Beste LA, Green PK, et al. Increased risk for hepatocellular carcinoma persists up to 10 years after HCV eradication in \\ patients with baseline cirrhosis or high FIB-4 scores. Gastroenterology 2019;157:1264-78.e4.
}

Submitted Nov 06, 2019. Accepted for publication Nov 30, 2019.

doi: 10.21037/hbsn.2019.11.27

View this article at: http://dx.doi.org/10.21037/hbsn.2019.11.27

Hepatocellular carcinoma (HCC) is the fifth most common cancer and the second most frequent cause of cancer-related death worldwide. Hepatitis $\mathrm{C}$ virus $(\mathrm{HCV})$ infection is one of leading cause of cirrhosis, that is the strongest risk factor for the development of HCC in Western countries $(1,2)$.

Until 2015, the only available treatments for HCV infection were interferon (IFN)-based regimens that had many limitations and very low rates of sustained virologic response (SVR) in cirrhotic patients (11\%) (3). The recent advent of IFN-free direct acting antivirals (DAAs) has deeply changed the treatment of HCV infection, reaching rates of SVR $>95 \%$ at any stage of liver disease (4).

Different studies showed that HCV eradication, induced by DAAs, significantly reduces, but does not eliminate, the risk of developing HCC $(5,6)$ and, therefore, cirrhotic patients should continue HCC surveillance after SVR (1). However, these studies are limited by short-term followup [longer mean follow-up of 2.93 years with a maximum observational time of 3.65 years (7)] and whether HCC risk falls over time remains unclear. Moreover, it is still debated if the risk of HCC is reduced in similar rates in patients treated with IFN-based compared to DAA regimens, because these two populations are different in many characteristics and not comparable.

In this scenario, Ioannou et al. published recently a paper showing the changing over time of HCC risk after $\mathrm{HCV}$ eradication and identifying the risk factors that limit the reduction of HCC risk in some patients (8). In this retrospective study, they identified, from Veterans Health Administration, the largest healthcare system in US, 48,135 patients $(9,784$ with and 38,351 without pre-treatment cirrhosis) all treated with HCV antivirals regimens from 2000 to 2015 all achieving SVR. Twentynine thousand thirty-three patients were treated with DAAs and 19,102 with IFN-based regimens. Moreover, during the follow-up period, extended to the first months of 2019, 1,509 incident HCC were identified. They collected baseline data and laboratory tests obtained within 6 months prior to antiviral treatment to calculate baseline fibrosis-4 (FIB-4) score and these tests were repeated after SVR. Although FIB-4 score is used to evaluate the advanced liver fibrosis, it has been shown to be strongly associated to HCC risk $(7,9)$. In this study FIB-4 score was analyzed as time dependent covariate in order to overcome the immortal time bias.

The authors showed that, among patients with pretreatment cirrhosis, those treated with DAAs and with baseline FIB- $4 \geq 3.25$, had higher annual incidence of HCC (3.66\%/year) than patients with baseline FIB-4 $<3.25$ (1.16\%/year). In DAA-treated patients with cirrhosis, the annual risk of HCC declined over years, decreasing from $3.8 \%$ /year in the first year after therapy to $2.4 \%$ /year by the fourth year. Instead, in IFN-treated patients, the annual risk of HCC remained above 2\%/year also after 10 years of SVR. 
In patients with a decrease from pre-treatment FIB$4 \geq 3.25$ to post-SVR FIB- $4<3.25$, the risk of HCC was reduced by $50 \%$, but the absolute annual risk remained above $2 \% / y e a r$. On the contrary, the minority of patients with an increase of FIB-4 score after SVR had higher annualized HCC incidence compared to patients with FIB4 persistently $<3.25$ (2.29\% vs. $1.02 \%)$. Moreover, patients without pre-treatment cirrhosis but with FIB-4 $>3.25$ had higher risk of HCC, without any decline over time, than patients with pre-treatment FIB-4 $<3.25$.

This study showed that FIB-4 score can be utilized to estimate HCC risk and its changes after SVR are associated with change of HCC risk. Moreover, the annual risk of HCC declining over time in patients treated with DAA, but not in those treated with IFN-based regimens, and it remains high in cirrhotic patients with FIB-4 $>3.25$. So, this category of patients could benefit of surveillance after SVR indefinitely.

The study underlines the importance of risk stratification model for HCC and identifies hepatic fibrosis, evaluated by FIB-4, as main risk factor. In fact, previous studies showed that cirrhosis with portal hypertension is significantly associated with HCC risk $(10,11)$. The achievement of SVR reduces the risk of liver related complications, but there are many other factors that have impact on HCC risk.

However, the study shows some limitations. First, the authors demonstrated that a reduction in FIB-4 after SVR was associated with a decline in HCC risk. However, it must be emphasized that, after SVR, the change of FIB-4 is often due to a reduction of liver transaminases causing by improvement of necroinflammation after viral clearance and not related to amelioration of liver fibrosis. So, this result needs to be investigated in more accurate manner.

Moreover, patients treated with DAAs have only 4 years of follow-up and the declining of HCC risk is not comparable to those treated with IFN-based regimens that have more than 10 years of follow-up.

This study identified a first simple way to stratify HCC risk, the FIB-4, calculable on pre-treatment data, allowing to evaluate which patients have a greater risk of HCC even after HCV eradication and could benefit from surveillance program. However, it is important to underline that HCC risk could be modified by other factors that are pre-existing or intervene after HCV treatment. For example, many studies have shown a strong correlation between metabolic comorbidities [type 2 diabetes mellitus, high body mass index (BMI) and concomitant presence of steatosis] and HCC risk. The presence of these comorbidities has been associated with both increased risk of HCC development and cancer related mortality $(12,13)$. For these reasons, European guidelines recommend that patients with cofactors for liver diseases, regardless fibrotic degree, should continue surveillance for HCC, even after HCV eradication (1).

\section{Acknowledgments}

Funding: None.

\section{Footnote}

Conflicts of Interest: All authors have completed the ICMJE uniform disclosure form (available at http://dx.doi. org/10.21037/hbsn.2019.11.27). The authors have no conflicts of interest to declare.

Ethical Statement: The authors are accountable for all aspects of the work in ensuring that questions related to the accuracy or integrity of any part of the work are appropriately investigated and resolved.

Open Access Statement: This is an Open Access article distributed in accordance with the Creative Commons Attribution-NonCommercial-NoDerivs 4.0 International License (CC BY-NC-ND 4.0), which permits the noncommercial replication and distribution of the article with the strict proviso that no changes or edits are made and the original work is properly cited (including links to both the formal publication through the relevant DOI and the license). See: https://creativecommons.org/licenses/by-nc$\mathrm{nd} / 4.0 /$.

\section{References}

1. European Association for the Study of the Liver. EASL clinical practice guidelines: management of hepatocellular carcinoma. J Hepatol 2018;69:182-236.

2. Global Burden of Disease Liver Cancer Collaboration, Akinyemiju T, Abera S, et al. The burden of primary liver cancer and underlying etiologies from 1990 to 2015 at the global, regional, and national level: results from the global burden of disease study 2015. JAMA Oncol 2017;3:1683-91.

3. Everson GT, Jensen DM, Craig JR, et al. Efficacy of interferon treatment for patients with chronic hepatitis C: comparison of response in cirrhotics, fibrotics, or nonfibrotics. Hepatology 1999;30:271-6.

4. Falade-Nwulia O, Suarez-Cuervo C, Nelson DR, et al. Oral direct-acting agent therapy for hepatitis $\mathrm{C}$ 
virus infection: a systematic review. Ann Intern Med 2017;166:637-48.

5. Singer AW, Reddy KR, Telep LE, et al. Direct-acting antiviral treatment for hepatitis $\mathrm{C}$ virus infection and risk of incident liver cancer: a retrospective cohort study. Aliment Pharmacol Ther 2018;47:1278-87.

6. Ioannou GN, Green PK, Berry K. HCV eradication induced by direct-acting antiviral agents reduces the risk of hepatocellular carcinoma. J Hepatol 2017;S01688278(17)32273-0.

7. Kanwal F, Kramer JR, Asch SM, et al. Long-term risk of hepatocellular carcinoma in $\mathrm{HCV}$ patients treated with direct acting antiviral agents. Hepatology 2020;71:44-55.

8. Ioannou GN, Beste LA, Green PK, et al. Increased risk for hepatocellular carcinoma persists up to 10 years after $\mathrm{HCV}$ eradication in patients with baseline cirrhosis or high FIB4 scores. Gastroenterology 2019;157:1264-78.e4.

Cite this article as: Cossiga V, Guarino M, Morisco F, Caporaso N. Risk stratification of HCC occurrence after $\mathrm{HCV}$ eradication: a complicate plot of risk factors related and unrelated to the previous viral disease. HepatoBiliary Surg Nutr 2020;9(4):511-513. doi: 10.21037/hbsn.2019.11.27
9. Kanwal F, Kramer J, Asch SM, et al. Risk of hepatocellular cancer in $\mathrm{HCV}$ patients treated with direct-acting antiviral agents. Gastroenterology 2017;153:996-1005.e1.

10. Carrat F, Fontaine H, Dorival C, et al. Clinical outcomes in patients with chronic hepatitis $\mathrm{C}$ after direct-acting antiviral treatment: a prospective cohort study. Lancet 2019;393:1453-64.

11. Lleo A, Aglitti A, Aghemo A, et al. Predictors of hepatocellular carcinoma in HCV cirrhotic patients treated with direct acting antivirals. Dig Liver Dis 2019;51:310-7.

12. Dyal HK, Aguilar M, Bartos G, et al. Diabetes mellitus increases risk of hepatocellular carcinoma in chronic hepatitis $\mathrm{C}$ virus patients: a systematic review. Dig Dis Sci 2016;61:636-45.

13. Morisco F, Guarino M, Valvano MR, et al. Metabolic disorders across hepatocellular carcinoma in Italy. Liver Int 2018;38:2028-39. 